\title{
Designing Learning Games and Tools for Karelian Language - Considerations Based on Beginners' Experiences of Gameplay
}

\author{
Leena Arhippainen \\ University of Oulu, INTERACT Research Unit \\ Oulu, Finland \\ leena.arhippainen@oulu.fi
}

\author{
Paula Alavesa \\ University of Oulu, Center for Ubiquitous Computing \\ Oulu, Finland \\ paula.alavesa@oulu.fi
}

\begin{abstract}
According to our knowledge, there are only few existing mobile games for learning Viena Karelian dialect and culture. Karelian is classified as a minority and endangered language. Different actions for revitalizing the Karelian language and culture have been made during the several past years in Finland and Russia. However, more effort is needed, especially to developed digital and easily accessible ways to learn and teach Karelian. This paper presents simple games developed for beginners to learn Viena Karelian. We also present findings from a small-scale user study. In addition, we propose a concept idea of the tool for teachers to create simple learning exercises.
\end{abstract}

\section{INTRODUCTION}

Karelian language is minority language and classified as an endangered language [1]. Karelian language is divided into two main dialects, which are Karelian Proper and Olonets Karelian (Livvi Karelian). Moreover, Karelian Proper is divided into North Karelia (Viena), and South Karelian [2-5]. Endangered Karelian language including its all dialects will require strong revitalization actions in the near future. It is important to find modern ways of learning and teaching language and culture of Karelian. The digital solutions should be designed for different age groups (small kids, teenagers, adults, or seniors) with various language backgrounds (Finnish, Karelian or Russian) and provide locationindependent solutions for self-studying.

Language and culture are traditionally learned from nongaming contexts, from formal studies, books, social interactions, and as native languages. Gamification is an approach which aims to develop games from non-gaming contexts by applying game design elements to engage learners (players) and increase their motivation [6-8]. The motivation and engagement of players are key factors for increasing the effectiveness in language and culture learning, especially with younger people. In addition, educational games with gamification can improve the fun experiences and knowledge acquisition, as an enhancement to face-to-face learning in the classroom [9]. The main aim of educational games is knowledge acquisition, which means that players can attain new information and gain new learning experiences [10]. It can increase the motivation and willingness of learners to learn, as an alternative for using a traditional method of teaching such as learning from books and face-to-face classroom interactions. Educational games in mobile or desktop can provide better learning environments than using only a traditional approach [9], [11], [12].

According to our knowledge, there are not many existing mobile or online games for learning Viena Karelian dialect and culture [13], [14]. The Kielimestari [15] application was published in 2009, and its beta version is available in Google Play. The purpose of this game is to increase awareness of Finland's minority languages such as Swedish, Northern Sami Language and Karelian. With this application a player can practice these minority languages. The game is visually pleasant and provides easy access for learning Finnish history and language information. In this game Karelian language examples are made in Viena Karelian. Moreover, there exists relatively old online game called Riputandupučas [16] which is a hangman-type game for learning Olonets Karelian (LivviKarelian). The database of this game includes only 510 words relating to nine different themes. A good feature in this game is that the Karelian keyboard is provided so the player can easily select the special letters with háček mark, for instance,

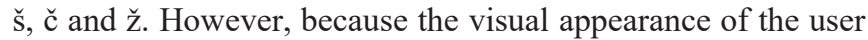
interface looks a bit old or dated, it might have some influences on user experience. This game is implemented only in Livvi-Karelian. The recently published Viena - Epic Kalevala Adventure [17] game has great visual design and sounds. It introduces a player to Karelian culture by narration, but the texts are in Finnish or English.

All these existing games are examples of an attempt to help people learn Karelian language and culture [15-19]. However, more gamified applications and serious games are needed both in mobile and web platforms for different user groups. In addition, it is important to provide these kind of learning applications for both Finnish and Karelians in Finland and Russia, Republic of Karelia. This is especially important because it helps communication between Finns and Karelians and thus enables revitalization of Karelian language. Karelian language changes all the time like languages in general, therefore just old collections of vocabularies are not enough, for instance, the online Dictionary of Karelian [18]. We need to update, create and maintain new vocabularies in Karelian and provide easy access to new words. Active native speakers 
and teachers do this kind of work already for instance, in social media.

In this paper, we present simple online games developed for beginners to learn Viena Karelian. In addition, we present findings from a small-scale user study. Derived of these, we also propose an concept of how teachers could create learning exercises. Finally, the paper is discussed and concluded.

\section{RELATED WORK}

The aim of gamification is to increase the motivation and engagement of users [20, 21]. It has been used in many contexts, however learning and teaching are the most common ones, which is also the case for serious games [8, 12]. So, while traditional educational settings, such as books, face-toface learning, and social interactions when learning language and culture are examples of contexts that have also traditionally been seen as non-gaming contexts, there is also a tradition of adapting gamification and serious games to this context. It is, in addition, important to notice that gamification can make those learning environments more attractive. Game elements for gamification are simpler than entertainment games because it focuses on the knowledge acquisition and learning process [9-11, 22] and gamification elements can be showed as levels, progress status, and score [6].

In educational games users can learn while playing the games with interesting and attractive playthroughs while learning. Also, educational games concentrate on engagement, simpler features, gameplays, and learning activities [10, 20]. Those aspects increase the willingness of users to learn and increase the effectiveness of knowledge acquisition. Educational games should be easy to play and focus on the educational aspects rather than social interactions that can be the goal of pure entertainment games [23]. Even simple entertainment games are saturated with language and known to enable unintentional language learning [24].

Research of educational games for English learning indicates that gamification can achieve better knowledge acquisition to improve listening, reading, and writing skills [25]. Moreover, those skills can be taught with video and audio materials to increase the effectiveness of learning, rather than by using only written texts [9]. It is important to notice that skills such as listening, reading, writing, and speaking can be taught with language learning games $[26,27]$ and games can make untiring tutors computers can provide repetitive and targeted feedback, regardless of time and location, which can be especially useful for grammar and vocabulary learning [24].

During our concept and game development we have found only some games relating to learning Karelian language. The online game Uuši vuoši [16] and mobile application Kielimestari [13] are games that support learning Viena Karelian. Old online game called Riputandupučas [16] is focused on learning Olonets Karelian (Livvi-Karelian).

There are also some games developed for teaching about the Finnish national epic the Kalevala such as Heroes of Kalevala [28], Väinämöisen matka [29], Sammon salat [30] and Viena - Epic Kalevala Adventure [16]. However, these Kalevala related games are not enough for Karelian language learning. There should be also implemented Karelian language examples in Kalevala context.

All these examples indicate that there are interests to teach Karelian language and culture to Finnish people. However, it is not enough. There should be put recourses and emphasis on teaching Karelian language to both Finnish and Karelian people. In addition, gamification applications and serious games should be provided for context-independent self-studies as well. Moreover, young generations should be involved in game development processes in order to create games that are interesting for young people and new learners.

\section{ONLINE VIENA KARELIAN GAMES FOR BEGINNERS}

This chapter presents the online games developed for beginners to learn Viena Karelian. These games have been coded with the languages HTML, CSS and JavaScript, using the program Visual Studio Code. All the images have been selected from an on-line archive of images available for noncommercial use for free [31]. For the content creation we investigated available materials, for instance, Viena Karelian study books [32-34] were acquired and studied, and the online Dictionary of Karelian [18] was used. Next, we present the online games, which were developed for learning and practicing Viena Karelian vocabulary.

\section{A. Crossword}

The current version of Crossword (Fig. 1) was designed to be used on computer with a drag and drop usage of the mouse. The player gets the words at the beginning of the game, so all the words have the same length, thus the player cannot deduce where the words go because of their length. Therefore, in this example, there is no thematic unit in the gameplay, so it can be considered a middle step between a beginner's and starter's learning level (easy-difficult). At the end of the gameplay, the player can read a word in the vertical, and then try to select the corresponding image from the three options.

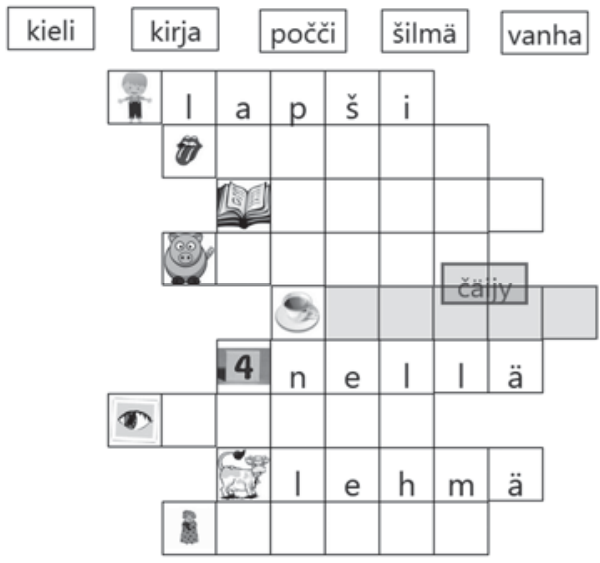

Fig. 1. The Crossword 1 game with the drag and drop interaction

In the other Crossword implementation (Fig. 2) the gameplay demands the player to show his/her basic or active knowledge of Viena Karelian. The words are no longer provided, and $\mathrm{s} /$ he must write them after clicking an image. Different versions of this crossword can be created, increasing 
the level of difficulty by mixing different topics and/or by substituting the images with definitions. This Crossword includes buttons with the special characters needed in Viena Karelian e.g. š and č, so that users do not find it problematic to fill letters by using unmatching keyboard language layouts.

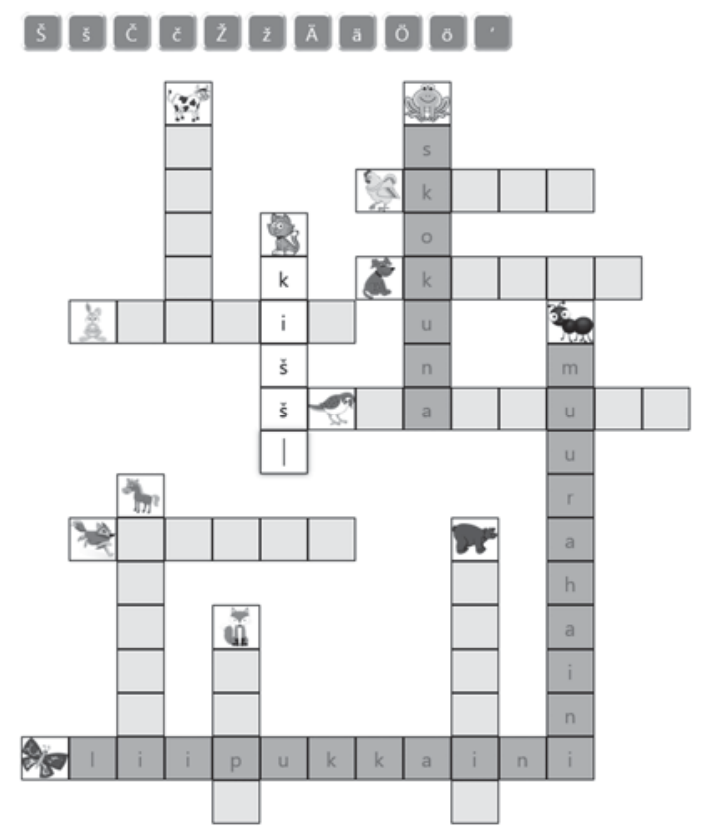

Fig. 2. The Crossword 2 game with writing interaction

\section{B. Wordsearch}

In this version, the player can select the level Easy or Difficult and theme: Animals, Family, Food, Body parts or Numbers. Difficulty of gameplay can be added by providing various themes and different number of letters. This Wordsearch game version (Fig. 3) is implemented so that first the program places correct words on the grid and then automatically other letters are added. The game works so that first a player clicks the first letter of the word and then the last letter, then word will be highlighted with coloring the letter boxes.

\section{ČÄIJY,OMENA \\ RIISSU, JUUŠTO \\ KAKKARA,HUTTU \\ BANANI, /ÄTELÖ}

\begin{tabular}{|c|c|c|c|c|c|c|c|c|c|c|c|c|}
\hline D & Z & C & M & A & K & F & M & M & Z & N & H & J \\
\hline Y & R & V & A & A & R & A & K & K & A & K & X & I \\
\hline L & X & D & I & A & P & J & S & X & O & J & O & A \\
\hline M & F & P & J & U & U & S & T & O & M & C & M & T \\
\hline M & O & U & T & T & U & H & O & C & E & L & O & E \\
\hline H & C & L & B & A & N & A & N & I & N & Q & T & L \\
\hline I & T & E & G & A & R & X & K & U & A & A & B & O \\
\hline H & H & S & I & Y & C & V & O & A & A & R & I & Q \\
\hline C & C & A & I & J & Y & K & X & E & C & E & J & S \\
\hline C & C & N & R & I & I & S & S & U & A & R & D & M \\
\hline W & Q & W & I & W & R & I & A & J & U & A & D & O \\
\hline Y & O & I & T & S & D & J & M & F & X & S & A & S \\
\hline C & F & U & Q & N & L & I & M & P & K & K & S & I \\
\hline
\end{tabular}

Fig. 3. Wordsearch game with the theme Food and the level Difficult
The Fig. 4 shows a more difficult version of the wordsearch, where only image clues are available for the player, who needs to guess the words first and then find them. When the player clicks the first and the last letter of the word $\mathrm{s} /$ he has found, the letters that become illuminated as $\mathrm{s} / \mathrm{he}$ advances through the rows and columns of the "letter soup". This helps the players to tracks down what they are selecting. Different levels of difficulty can be created by mixing the thematic of the wordsearch as well as by having definitions instead of images as clues for finding the words.

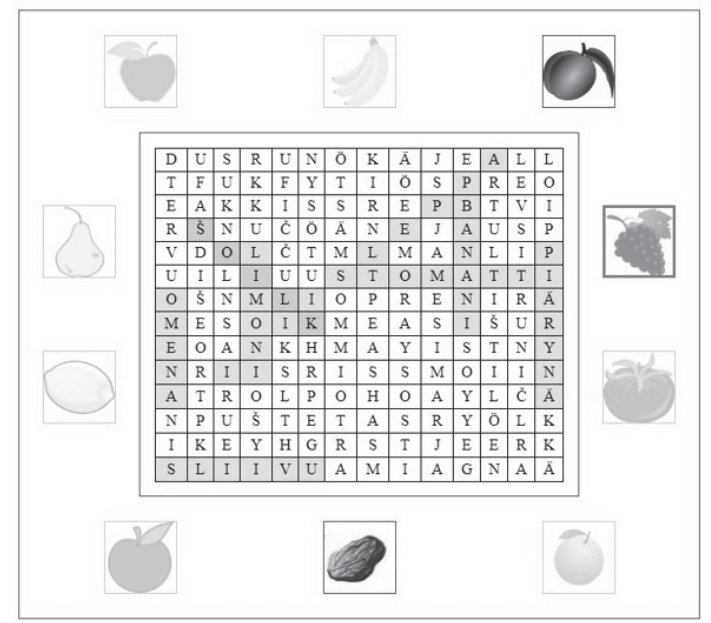

Fig. 4. Wordsearch game with theme: fruits

\section{Memory games}

In one of the memory games (Fig. 5) the idea is to provide Finnish and Viena Karelian word with images, so a player can easily begin to remember which words are similar in Viena Karelian and Finnish, for instance 'koira' is 'koira', (dog), and which are different like 'liipukkaini' is 'perhonen' (butterfy) or 'skokuna' is 'sammakko' (frog). In this game a player can select the theme (Body parts, Animals, Food and drinks and Numbers) and the number of cards (8-20 cards).
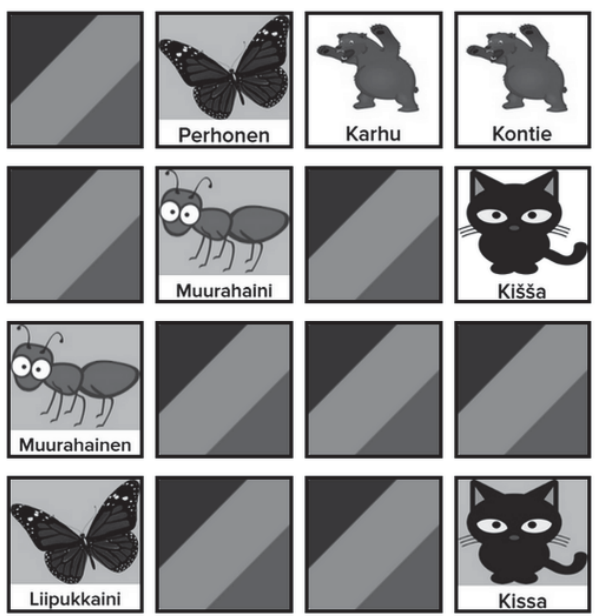

Fig. 5. Memory game (version 1) with eight Finnish - Viena Karelian card pairs with theme: animals 
The other version of the memory game (Fig. 6) is a bit challenging because the player needs to match a given image with the corresponding word. This version is more useful when all the words belong to a thematic group, like in the example, words related to vocabulary of body parts. The third version of the memory game is developed so that a level of difficulty is increased: after encountering a pair, the player needs to use the word in a sentence, derivating it according to the grammar rules of Viena Karelian (Fig. 7). The idea behind this game task is that words do not always stay the same in Viena Karelian. Like in Finnish, depending of the grammar rule the word is playing within the sentence, the word needs to be derived. In this way, students not only practice their vocabulary, they also revise the derivation of words according to a sentence. After trying and answering wrongly a player has a possibility to see the correct answer (Fig. 7).

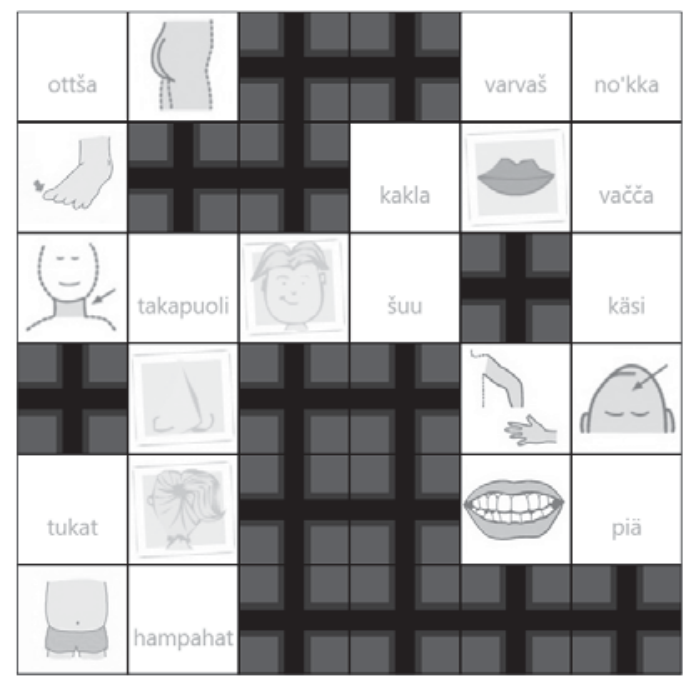

Fig. 6. Memory game (version 2) with 18 Viena Karelian word - image card pairs with theme: body parts

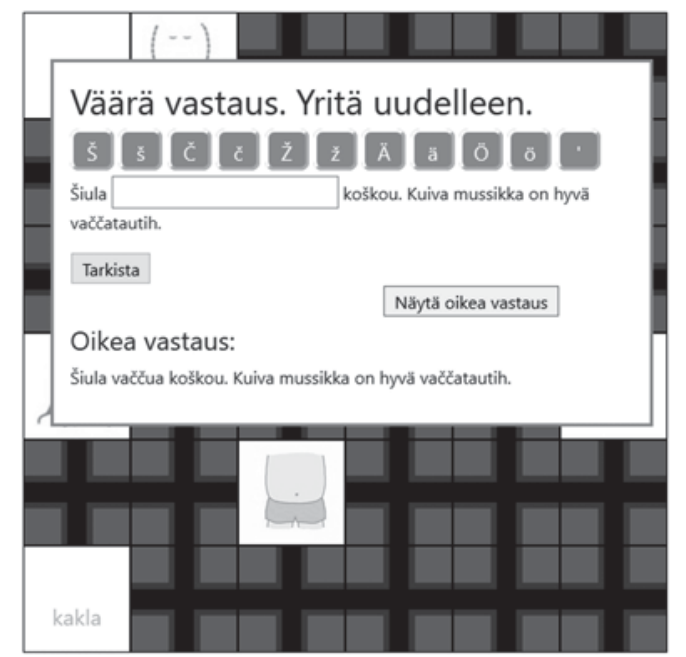

Fig. 7. Memory game (version 3) with a sentence practice after finding each image-word pair.

\section{Five Multiple-choice and Matching games}

In this multiple-choice game, the idea is to connect the right Viena Karelian word with the image. In the easy version of the game words are different animals like the example image in the Fig. 8 A. It is a bit easier to find the correct word if the player knows a bit Viena Karelian or some words can also be guesses based on Finnish language, for instance, 'repo' is 'kettu' (in Finnish also repo or repolainen is used), 'hukka' is 'susi' (wolf) and 'muurahaini' is 'muurahainen' in Finnish. The level of difficulty in this game can be increased to provide one correct word and other words which are quite similar with the correct one like in the Fig. 8B, where 'kontio' is similar than in Finnish and 'konttilaini' is wrong, but it is similar to Viena Karelian words like muurahaini (ant) or liipukkaini (butterfly). For new learner it is difficult to remember which words are similar and which end "ie" or "ni". Likewise, some words are totally different than in Finnish, like Finnish 'sammakko' is 'skokuna' (frog) in Viena Karelian and 'liipukkaini' is perhonen in Finnish.
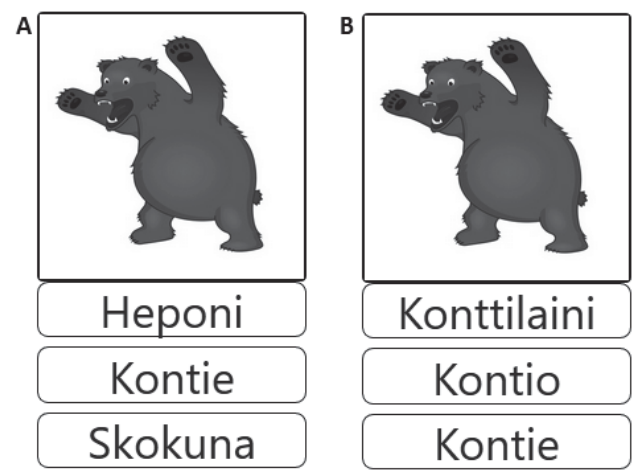

Fig. 8. In this game a player need to select the correct word with the image in A) easy and B) difficult game levels

The aim of simple connecting games (Fig. 9-12) is to support an approachable way to start to learn vocabulary by connection either words with translations or depicting images. It is important to provide a lot of different games with the various difficulty levels so the player can select those that are useful or interesting for her or him. Also, it is important to provide different games for different age groups. In addition, teachers can select to use these games as exercises with pupils or students who have different language skills. Especially it is important to provide an easy drag and drop or click and click interaction using familiar paradigms for interaction.

In this game (Fig. 10) the idea is to practice words according the certain themes, for instance, weekdays. The player can select the level of difficulty. For example, in the Fig. 10 the player has selected difficult level and got five options to select a translation for word 'perjantai' (Friday). In the given options one is correct 'piätinččă' and others are wrong ones, but quite similar such as: 'päätinččä', 'piätintčä', 'piätinccä'. 'piätäntšä', 'piätinkkä', etc. This type of game task is more difficult also to people who have studied Viena Karelian [22]. 


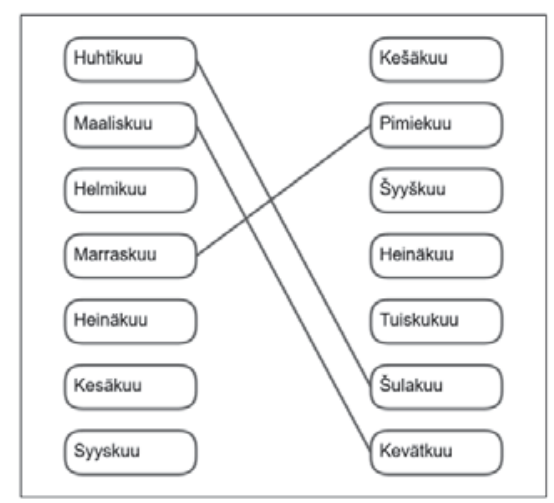

Fig. 9. Connect Finnish word with the correct Viena Karelian word

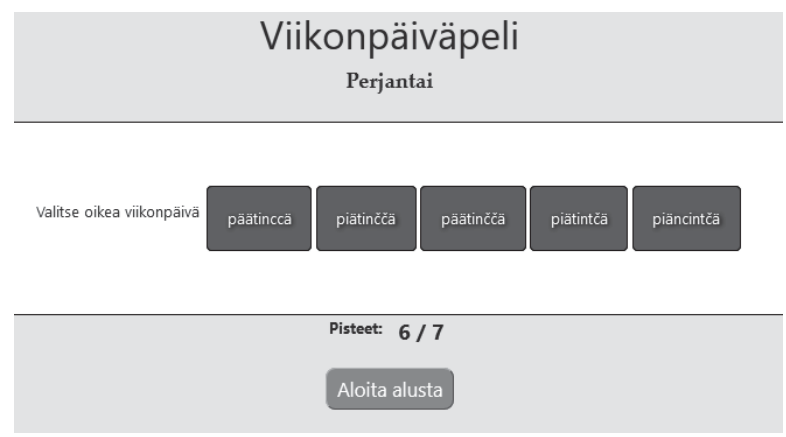

Fig. 10. In this game a player needs to select the right translation for 'perjantai' (Friday) from the given options.

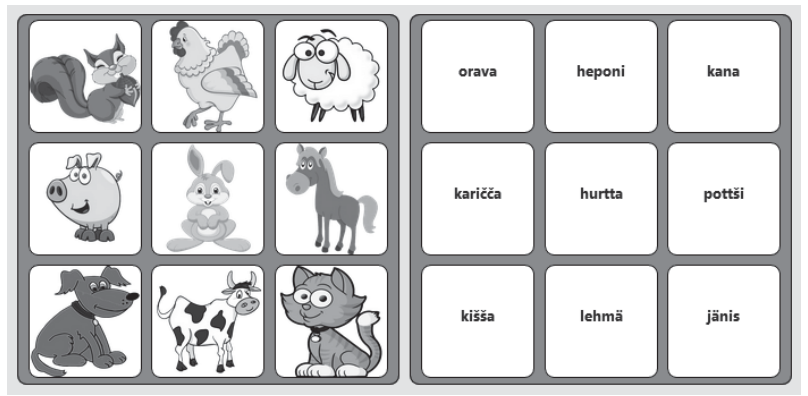

Fig. 11. In this game a player needs to select the correct Viena Karelian word for the corresponding image.

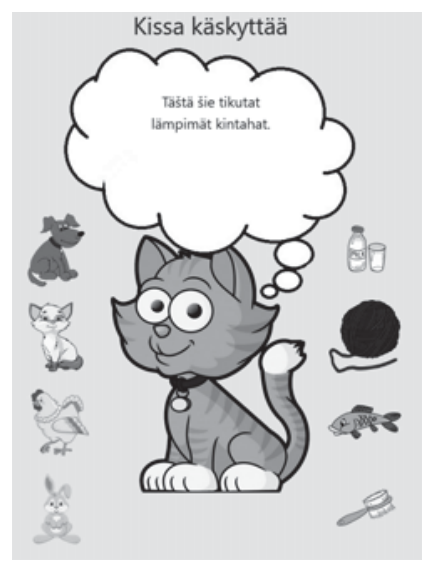

Fig. 12. In the Cat commands (Kissa käskyttää) game a cat gives a hint what she would like to have a player to give her.
In the Cat commands game (Fig. 12) a cat gives a hint what she would like a player to give her. The sentence examples are Viena Karelian. This game could be nice for small children if the cat says the sentences and then they could drag and drop items to cat.

\section{USER EXPERIENCE EVALUATION}

In this chapter, we present the test settings, participants and user experience findings relating to the online games.

\section{A. Test settings and Participants}

We conducted user experience evaluation with five participants, whose age varied from 4 to 72 years old. In this test we had two girls under school age (4 and 6 years) and two boys, who are in comprehensive school (11 and 15 years), and one senior male. All participants were beginner learners in Viena Karelian. The senior male had studied Viena Karelian in a club for over a year. The three youngest participants had learned some Viena words in their Viena related hobbies by singing, playing, or acting. They all commented that they can understand Viena Karelian based on the Finnish language and they mainly know some basic words or can say some simple sentences.

We collected user experiences by interviewing and observing during a mix of gameplay and game walkthrough. The process of the evaluation is depicted in the Fig 13. This paper focus on the findings of the phases 2-5 (Fig. 13). Participants' age group was taken into account during the evaluation process and tasks due two of participants were small illiterate child.

Fig. 13. The evaluation process with qualitative interview and observation.

Each test took from one to two hours in total. All our own online games were tested on laptop with mouse and keyboard interaction (Fig. 14A). In addition, for instance memory games and Cat commands were tested on mobile phone as well (Fig. 14B). Two mobile applications for Android OS (Viena - epic Kalevala Adventure [17] and Kielimestari [15]) were used only from mobile phone. These applications were not designed as language learning purposes, but we wanted to show them to the participants because they are relatively new, and they provide culture and minority language knowledge for players. 
Also, their audio-visual design was more advanced than in our online games. However, in this paper, we do not focus on the player experiences with these applications.
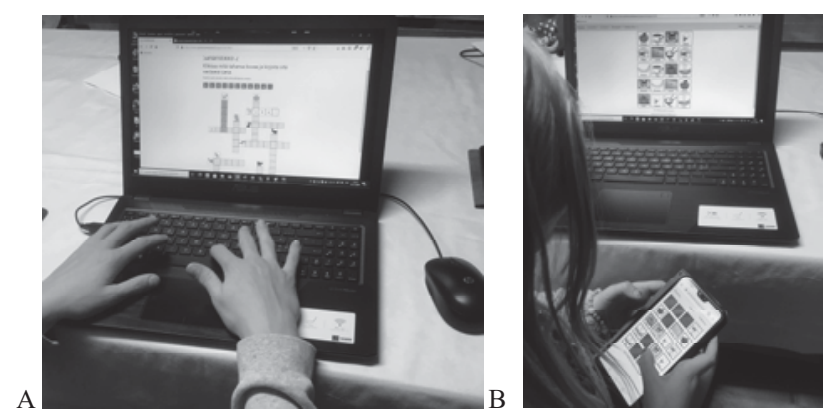

Fig. 14. A) Participants tested games on laptop and B) some games on mobile phone as well (e.g. Memory games, Cat commands).

Although our sample is relatively small, we see it important to report these subjective experiences relating to these simple online games. Also, even though the games are in their early phase and there exist many usability and visual design issues, we found interesting user experience aspects from different user groups.

\section{B. Experiences of crossword games}

According the participants the first Crossword was easy and quick to play just by dragging and dropping the given words. They started with the easiest words and succeeded to fill all boxes. The other Crossword version was harder for those who did not know or remember so many Viena Karelian words. The Fig. 15 shows how one participant (ID1) succeeded to write almost all word, except two (frog, butterfly). He commented that he has heard those words, but just cannot remember what they are. He also mentioned that by playing this game (Fig. 15), he can see how much he have learned Viena Karelian words. He was a bit irritated that he did not remember these two familiar words. When he wrote ant, he first wrote Finnish version 'muurahainen', but then he noticed that the game does not accept the word. Then he remembered that it must be 'muurahaini'. It was interesting that he had learned that a cat is 'kišša', not 'kissa' like in Finnish.

The most advanced participant in Viena Karelian (ID5) was able to write all words correctly. In this game, only the bird image was a bit difficult for him, because he said that the image is small or unclear, and he cannot know that does it mean bird or certain species of bird. Finally, he figured out the word based on the letters he got from word hints: _ a (varpuni = sparrow). 'Varpuni' is varpunen in Finnish.

Participant (ID4) liked crosswords the most, but he commented usability issues, for instance, he would have liked just to click the letter boxes and start writing. Now the game was developed so that first a player needs to click an image and then the letter boxes turned white and became active and cursor appeared in the box. Participant (ID4) would have liked to cancel a letter by using a back button of keyboard, but now removing a letter was so that a player needed to use the mouse for changing the cursor location.

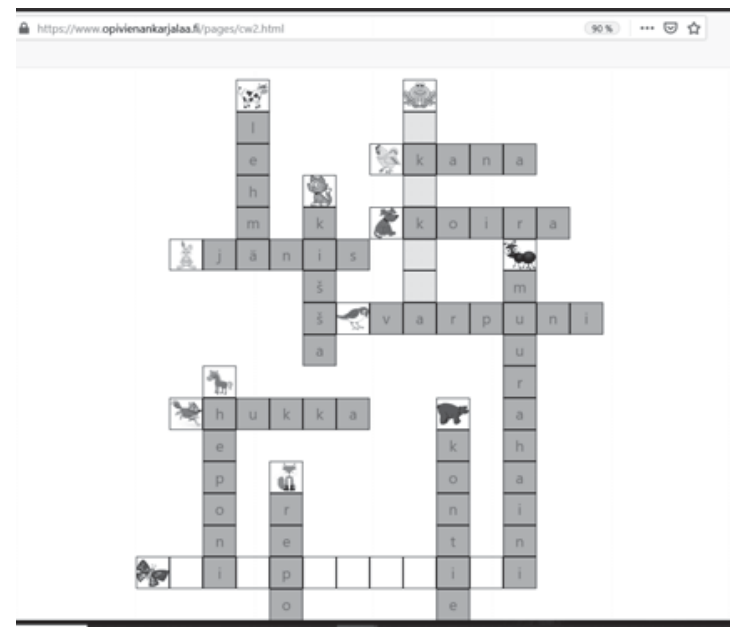

Fig. 15. Participants tested some games (Crosswords) a) only on laptop and some also b) on mobile phone (Memory game).

When a player writes a word wrong, the game shows it red and then the wrong word disappears. One participant (ID5) suggested that it should not disappear, instead it should show that the given word was wrong and then a player could correct letters. Now he had always to write the whole word again.

\section{Experiences of Searchword games}

The Searchword games were perceived nice and easy games in general. Especially, one participant (ID5) liked this type of games. He was the only one who managed to find words in the Fruit games which provided only image hint (Fig. 16). He first found 'piärynä' (päärynä, a pear), then 'tomatti' (tomaatti, a tomato), then 'marja' so he found 'mesimarja', by chance. Mesimarja is berry in Finnish, but in this game, it was a raisin (rusina in Finnish) [18]. He commented that we would not know what a raisin is in Viena Karelian, but now he learned it by chance, because he found it from the letters and the image of the raisin turned inactive. Then he tried 'limon' (a lemon) but the correct word would have been 'limoni', so then we moved forward and tried another wordsearch game (Fig. 17).

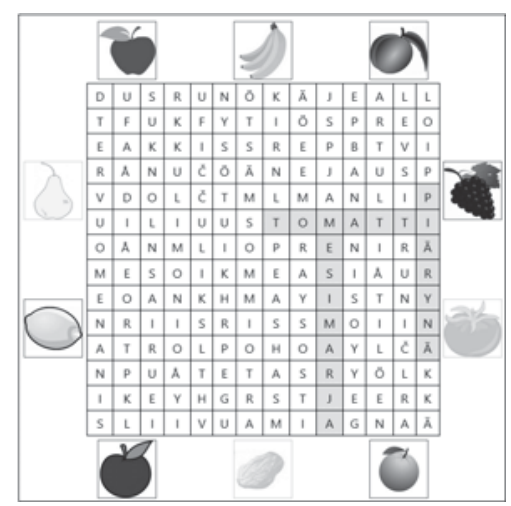

Fig. 16. The participant (ID5) was the only one who found words in this game.

The participants (ID5) proposed that the game should contain points but no time limit, because that would cause too much pressure. Also, he proposed how points could appear 
and how the visual design could be improved. In the current implementation, the background was white, and buttons were grey. Also, participants (ID1, ID4, ID5) proposed that there should be both images and text, at least on easy level, because it would be easier to understand images and learn new words in Viena Karelian. In this example, some words were like Finnish, but some totally different. For beginners it can be challenging to learn or know which words are similar.

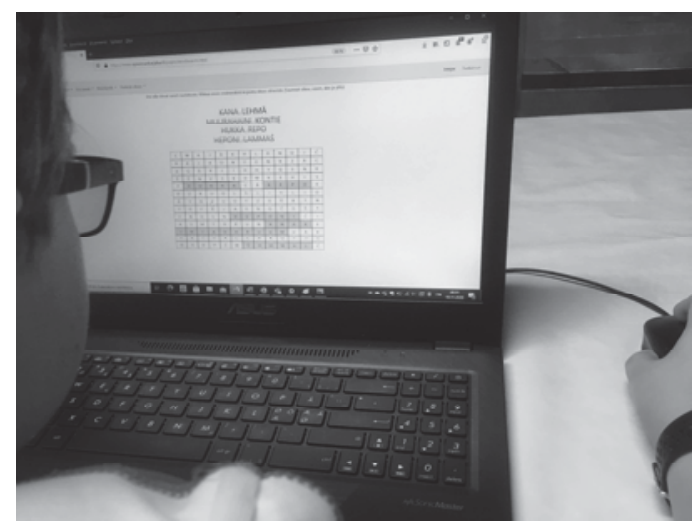

Fig. 17. The participant (ID5) selected the difficult version in this Searchword game and tried all themes. He wanted to find all words.

\section{Experiences of memory games}

The senior participant (ID1) liked the Memory game version 1 the most as he commented: "I give ten points to this game; this is good for all ages. You can easily see what these words are in Viena Karelian" (Fig. 18). He liked this game on both devices: computer and mobile phone. Based on the study, this game was perceived as good for both language learning purpose and entertaining. To increase learning aspect, the game could be further developed so that card content in said Viena Karelian, and thus a player would learn language just by playing (clicking cards), without a need to read cards. Participants proposed also that they would like to have both single and multiplayer option. One participant (ID5) even asked that can he play these games with his glass mate. Also, scores were regarded as important by all participants.

The other two versions of the memory games were perceived more difficult, partly because of difficulties to interpret some images in this game images did not include text at all and therefore, for instance, images for mouth and teeth were misunderstood. Also, the youngest participants thought that a happy face depicted joy, even though it was a head (piä). The small children preferred more the memory game 1, because there were text cards without image. Maybe voice indication would have helped the situation. Another reason why the Memory game 3 was perceived difficult was the grammar task. Two of the participants were so beginner Viena Karelian learners that they were not able to get words derivated correctly. For instance, the participant (ID1) tried to derivate 'vačča' word as in Finnish grammar. After two wrong answers, the participants was able to see the correct answer which was: 'Śiula vaččua koškou. Kuiva mussikka on hyvä vaččatautih’ (Fig. 19). Also the younger participant (ID4) commented: "How I can know how to write it?". This indicates that we should have games which first teach grammar rules. However, one participant (ID5) was able to derivate words and get several sentences correct. Actually, the player liked this memory game the most. He even commented: "This game was the best because you can use the word. It would be even better if I could create own sentences from the words."

Even this game feature seemed to be difficult for beginners it was perceived useful and teaching. Senior participant commented that it is more interesting to learn grammar with this type of system that from the books. He read the sentence aloud and said that it is good to have different types of games and repeat words and sentences. He was able to understand sentences based on the Finnish, but it would be difficult to write. Participant (ID4) did not regard this type of game as entertaining. He thought that it was more like learning task and thus not so interesting. Instead, participant (ID5) who was the most advanced in Viena Karelian noticed that he even learned new words by playing this game, for instance, he said: "Ah is 'kakla' kaula (neck)? I didn't know that. It is nice that words are in Viena so you will learn."

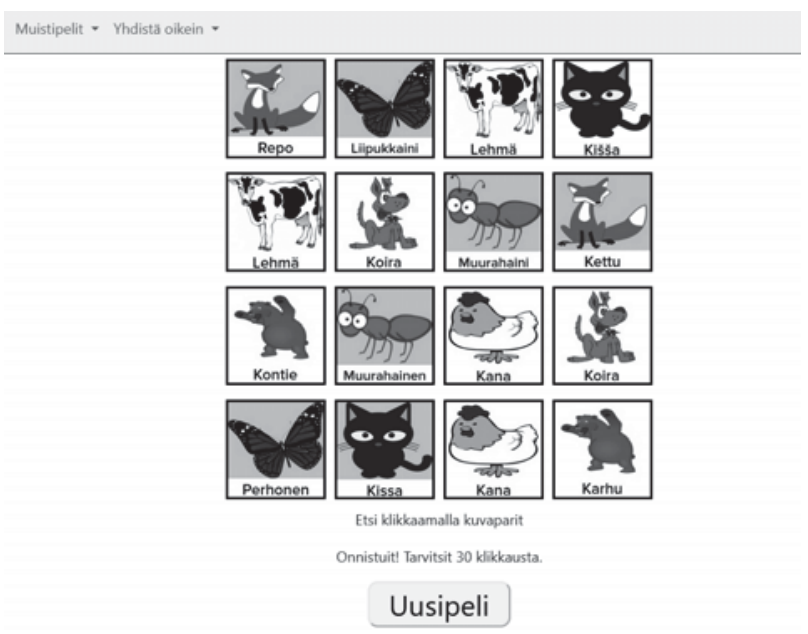

Fig. 18. Almost all participants like Memory game with images and Finnish and Viena Karelian words because it was easy and fast to use

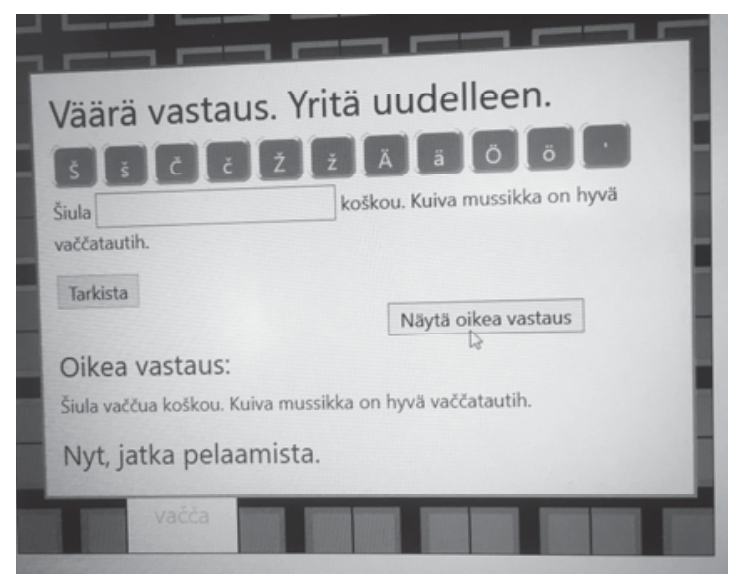

Fig. 19. The participant tried to derivate vačča word in a given sentence example. First he wrote vaČČa with big letter by chance and then vaččaa, which were both wrong. After two wrong answers, the player was able to see the correct answer, which was 'vaččua'. 
The participant (ID5) wanted to try this game also on mobile phone (Fig. 21). Even though the screen was small, and he needed to zoom and the keyboard blocked the view, he did not complain, but continued playing and he was happy when he succeeded to derivate the word correctly.

All participants commented that they would prefer playing these games on computer, because the screen is bigger, and writing is easier. In addition, they would have like to have games also on mobile phone, because then it would be easy to play anywhere. Also, social element was important, especially younger participants would have liked to play together with friends.

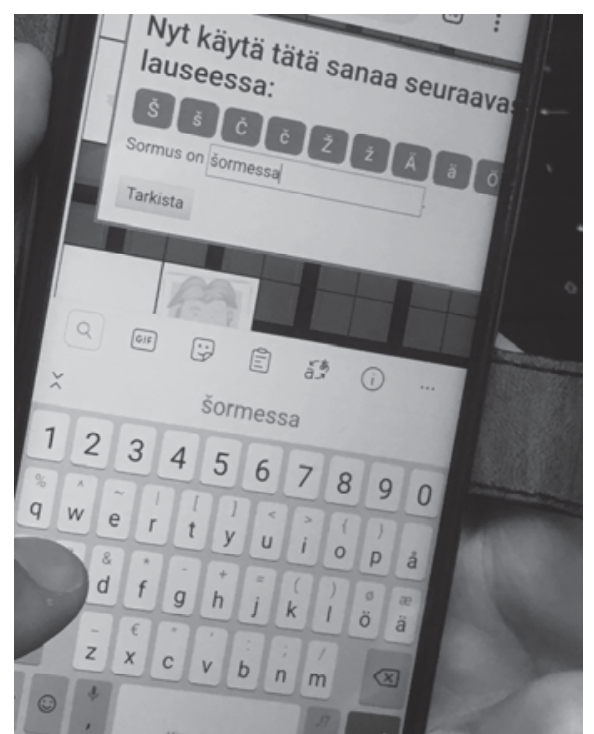

Fig. 20. The participant (ID5) wanted to try this memory game also on mobile phone

In this game, the other side of the cards were designed as the old flag of East Karelia. The senior participant (ID1) liked the design, because the flag was familiar to him from his childhood. Instead, the younger participant (ID4) did not like it because according to him, it was unclear visual design as the cards were not separated with empty space between them. This made flag's shape mixed with cards next to them and another square appearing (Fig. 20).

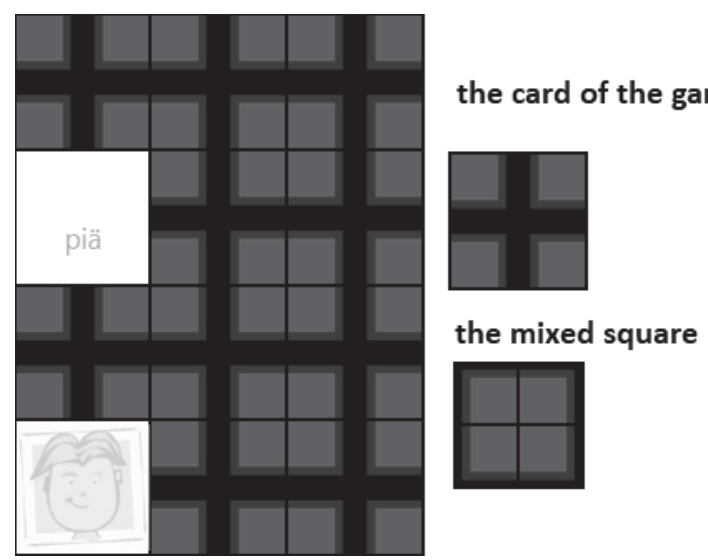

Fig. 21. The participant (ID4) did not like that cards were placed side by side without empty space between them, because the shape of the flag with borders caused another square appearing.

\section{Experiences of five multiple-choice and matching games}

Participant (ID4), who played first an easy version of the Multiple-choice game, selected correctly Kahekšan' (Fig. 22A), which is 'kahdeksan' in Finnish. He commented: “This is clear. This is almost like Finnish. This should be more difficult, so that there should be only small differences [between word options]". Then he played the difficult level of the game. The Fig. 22B shows the example how the game is more difficult when there are only small differences between options. The participant (ID4) selected wrong answer this time when he selected based on Finnish language. His selection was 'Kyynärpiä' which is in Finnis Kyynärpää. The right answer was 'Kyynäšpiä'. Another interesting example was that when the participant just quickly played the easy version, he still learned correct words, for instance, he learned 'nellä', which is four (4, neljä in Finnish) and he remembered that when he played the more difficult version.

The game (Fig 9) where a player needs to connect Finnish word with Viena Karelian word was perceived as boring and it was seen more like a language task. The participant (ID5) proposed that Finnish word should be image, not text and two participants (ID5, ID4) commented that there should be a possibility to correct own mistake selections. In the current implementation the selection was locked immediate after clicking.

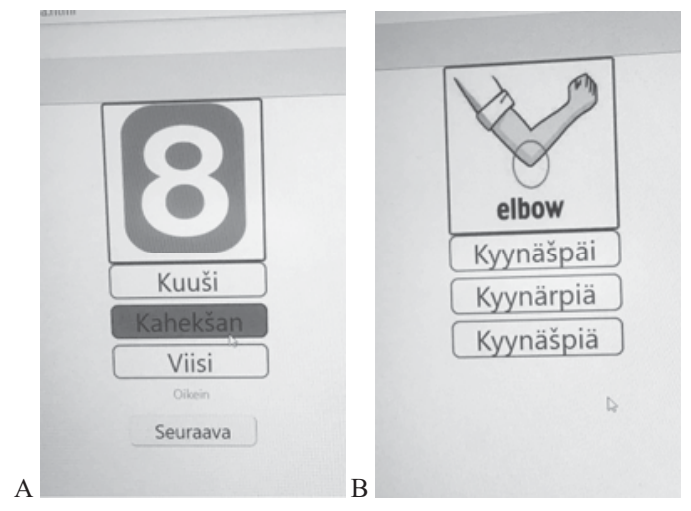

Fig. 22. Participant ID4 played first easy version with the theme Numbers and then difficult version with the theme Body parts

The game (Fig 11) included image and Viena Karelin text, but the interaction was a bit unfinished, because the imageword pair just disappeared when finding the pairs correctly. Also, interaction was not so clear, because participants needed to figure out is the interaction click and click or drag and drop based. This game does not include any instructions.

In this game (Fig. 11) the participant (ID5) wondered that why there is now 'pottsi' and it the Crossword I game it was 'počči' (pig). This is important issues. Of course, in many languages there can be synonyms (porsas, sika in Finnish) for the same item or childish expressions like piglet (possu in Finnish). In addition to that, in Viena Karelian there can be old expressions and modern expressions, for instance, in older study books [35] there is not š letter, but in newer books it is used [32-34, 36]. Likewise, there are regional differences in words how they are written. Also, the Online dictionary is implemented based on the six paper dictionaries published in 
1968-2005 [18]. Therefore, the game developers should take into account that which database they can use and should they provide several word versions for certain words. Likewise, in this game the participant (ID5) asked that what is 'hurtta' because he did not know that 'hurtta' is a synonym for a dog like in Finnish. However, maybe in Finnish it is not a nice word for dog, but in Viena Karelian it means big hairy dog according to the dictionary [18].

The weekday (Fig. 10) game was perceived as difficult but interesting from language learning point of view, because the differences between words is so small, only one or few letters. The game requires concentrating on words and cannot be selected correctly only based on Finnish language. The game mechanism was perceived as easy and maybe a bit boring.

The 'Cat commands' game was regarded as playful and easy to understand (Fig. 12). In this game, examples sentences gave a hint like 'Sillä on pruuni karva' (It was a brown hair coat). The player can try to quess that it means dog without knowing the colors at all. When the cat gave hint: 'Miula himottais leikkie ruškien lankakerän kera' (I would like to play with a red ball of yarn), one participant (ID4) commented that that ball is red not brown, because he did not know that in Viena Karelian red is ruškie and brown is pruuni. In Finnish red is 'punainen' and brown is 'ruskea'.

In the tests with illiterate children, the moderator read aloud in Viena Karelian what the Cat was thinking or asking. Then the participant gave the item to the cat. On the computer this was implemented as drag and drop interaction and on mobile phone the game worked by tapping the item (Fig 23). The cat indicated if the given item was right by head nodding or wrong by showing a tongue, and when the item was right the new sentence appeared in the thinking bubble. The one participant (ID5) proposed that the cat could spin when the item is correct and meow when the item is wrong.

This game could also include different difficulty levels, themes, and sentence examples with audio. The participant (ID5) ideated that there could be a room as a background and items could be on different places like on shelves. Also, in the test with the participant (ID3), we discussed that instead of the cat there could be a Vienakarelian girl and the player could give Karelian clothes to her.

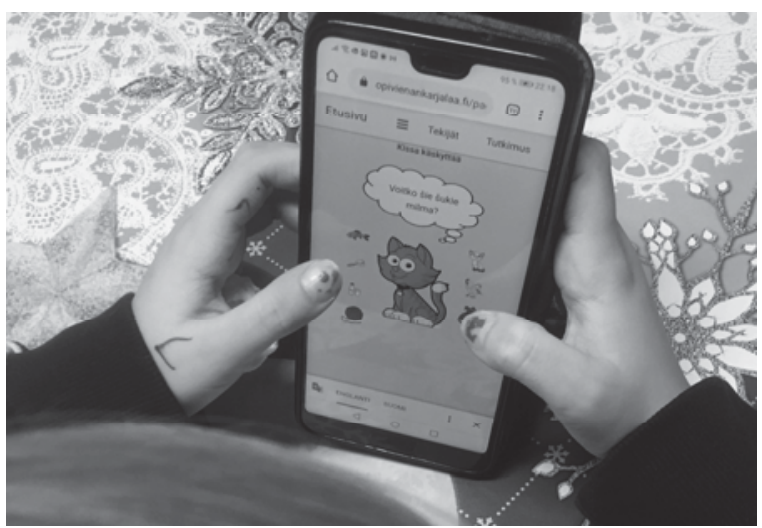

Fig. 23. The illiterate participant ID3 played 'Cat commands' game from mobile phone and the moderator read the Viena Karelian sentence what cat was thinking. Then the participant tapped the item the cat wants.

\section{E. Summary of the findings}

All participants had positive attitudes towards these simple games. However, the 15-year old boy (ID4) preferred to play games more for entertaining purposes than for learning languages. From these games he preferred crossword type of games. The 4- and 6-year old girls (ID2, ID3) liked memory game with images because it included different topics (e.g. animals, foods, numbers) and Cat commands game because, it was easy and included images. They would have liked the cat to talk Viena Karelian. The oldest participant (ID1) liked all games as he commented that "it is important to have different types of games that you will not get bored... and it is important to repeat words in different games so that you will remember them". His favorite game was the first memory game, where was images with Viena Karelian and Finnish words. The 11years old boy (ID5) was the most advanced Viena Karelian speaker, even though he was also a beginner. He enjoyed playing these online games and he was interested in learning Viena Karelian while playing. He also commented user interface design and proposed game ideas. His favorite game was the third memory game version with the grammar task. He would have liked to create own sentences as well.

In this test we selected different age group in purpose. It was interesting to perceive how senior participant (ID1) read aloud words and sentences and were very keen on learning language and culture. This person had studied Viena Karelian a bit in a club, and it was interesting for him-self to notice that he had learn some words and was able to play these games. we did not make any language tests for the players, but they commented their own language skills and progress. In addition, it was interesting to notice that the youngest participants were keen on playing and learning Viena Karelian. As the six-year-old girl said: "Next time, give me a more difficult game".

During the gameplay participants often commented the visual design of the game's user interface, and the visual design of the images. In the current implementation images were from free internet sources and were not necessarily designed by a graphical designer. Developers had used those images that they had found, and which were suitable for their game example. However, it was interesting to notice how the 11-year old boy commented fruits in the Searchword game by saying that some images are $2 \mathrm{D}$ and some $3 \mathrm{D}$. In addition, for all games he ideated how the visual design could be improved. The appearance of images was a critical issue in the situations where the meaning was misleading or ambiguous. This type of situations happened with over ten images and all age groups had difficulties to understand some images correctly.

Based on the participants' experiences we noticed various usability and visual design improvements for all games. We were aware of some of these issues because these games were still in the early phase and they were originally developed for research purposes. However, these implementations and user study findings can provide valuable information for further game development in minority language context. The following table (Table I) summaries the main user experience aspects that we found from this study. Some of the topics are very basic user interface design and development issues, but 
they are important to mention. When developing games for minority language context, it is important to consider that players' technological skills can vary and therefore the user interfaces should be very easy and fast to adopt [22]. However, even if the game design is simple, it is not allowed to be boring or useless. The game should provide some key elements for learning and maintaining language and culture knowledge for all age groups. That is a challenge.

TABLE I. UX ASPECTS TO CONSIDER IN GAME DESIGN

\begin{tabular}{|c|c|}
\hline UX aspects & Comment \\
\hline \multicolumn{2}{|l|}{ Learning } \\
\hline Language & $\begin{array}{l}\text { Provide various types of learning games for } \\
\text { different age groups and skills backgrounds. }\end{array}$ \\
\hline Culture & $\begin{array}{l}\text { Provide culture knowledge also in the basic game } \\
\text { examples (e.g. specific food, costume). }\end{array}$ \\
\hline Own progress & $\begin{array}{l}\text { Provide a possibility to keep track of own } \\
\text { progress during the gameplay and between } \\
\text { different games. }\end{array}$ \\
\hline Content & Correct content. Old and modern language. \\
\hline \multicolumn{2}{|l|}{ Visual design } \\
\hline Images & $\begin{array}{l}\text { Provide clear unambiguous images avoiding } \\
\text { misunderstanding of the meaning. } \\
\text { In design, take into account age group. }\end{array}$ \\
\hline Texts & $\begin{array}{l}\text { Provide easily understandable text content and in } \\
\text { a proper size depending on the context. }\end{array}$ \\
\hline Indication & $\begin{array}{l}\text { Provide clear audio-visual indication in different } \\
\text { phases of the gameplay. }\end{array}$ \\
\hline \multicolumn{2}{|r|}{ ( } \\
\hline Interaction & $\begin{array}{l}\text { Provide clear ways to interact on different } \\
\text { platforms (e.g. click-click, drag-drop, tapping) }\end{array}$ \\
\hline $\begin{array}{r}\text { User interface } \\
\text { design }\end{array}$ & $\begin{array}{l}\text { Design the user interface by following standards } \\
\text { and UI design guidelines for avoiding simple } \\
\text { usability problems. }\end{array}$ \\
\hline \multicolumn{2}{|l|}{ Experience } \\
\hline Guidelines & $\begin{array}{l}\text { Design UI so that it guides a player. If guidelines } \\
\text { are needed, design them consistent and easy to } \\
\text { find and understand. }\end{array}$ \\
\hline Gameplay & $\begin{array}{l}\text { Provide a smooth flow during the gameplay (e.g. } \\
\text { tasks, time, scores, narration, competition) }\end{array}$ \\
\hline Social aspects & $\begin{array}{l}\text { Provide single and multiplayer options when } \\
\text { possible. Revitalizing a minority language require } \\
\text { community co-operation and new learners. }\end{array}$ \\
\hline
\end{tabular}

\section{A TEACHER'S TOOL FOR CREATING EXERCISES}

This chapter presents a tool concept, that one of the game developers implemented. The idea in this tool is that teachers could use it for creating exercises in an easy way. As mentioned in the related work, one benefit of games for language learning is that games can be relentless tutors and provide repetitive tasks for learning vocabulary [24]. However, expert guidance can provide more complex tasks and being able to curate the game content keeps it current, and enables expansion to other languages. The Fig. 24-26 show the user interface of a tool to produce exercises following a series of straightforward steps. All images used in the exercises have been selected from an on-line archive of images available for non-commercial use for free [31]. In the tool the teacher's main tasks are the following: 1) Selection of the exercise type 2) Selection of words, 3) Re-organization of the format of the exercise and 4) Finalizing the exercise.
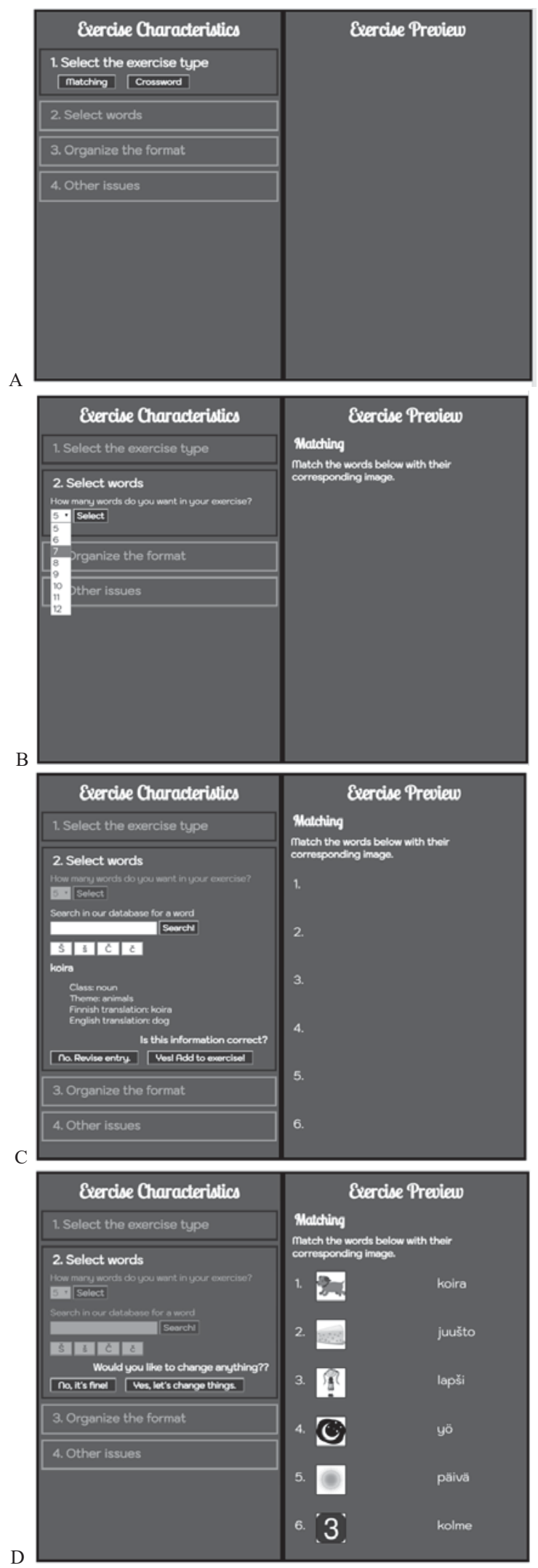

Fig. 24. A)A start page for doing exercise, B) A teacher selects the number of words he/she wants for the exercise and C) starts to select or add words. D) The teacher has selected six words (on the right). 
The teachers select from a list the kind of exercise they would like to have (1. Select the exercise type). The current prototype only includes matching exercises and crosswords, but it should include a longer list with, for instance, wordsearch exercises, memory games, true or false exercises, etc. (Fig. 24A) The next step (2. Select words) includes the following phases:

1) Selection of number of words in the exercise: The teachers can select the quantity of words they want to include in their exercise. Here the limits is set between 5 and 12 so the exercises are not too short or too long. This feature establishes that the exercises are always vocabulary-related, but in the future other alternative can be added in the same way as the aim is to add different types of exercises. (Fig. 24B)

2) Selection of words from the glossary: The teachers use the search engine to check a glossary that we are constructing beforehand. If the word does not exist in the glossary, the teachers can add new entries. If the word in the glossary is somehow incorrect, the teachers can revise it. (Fig. 24C) As they advance selecting words, the words appear on the preview section on the right. In this way, the teacher can keep track of which words have they already selected and have an image of how the exercise will look at the end.

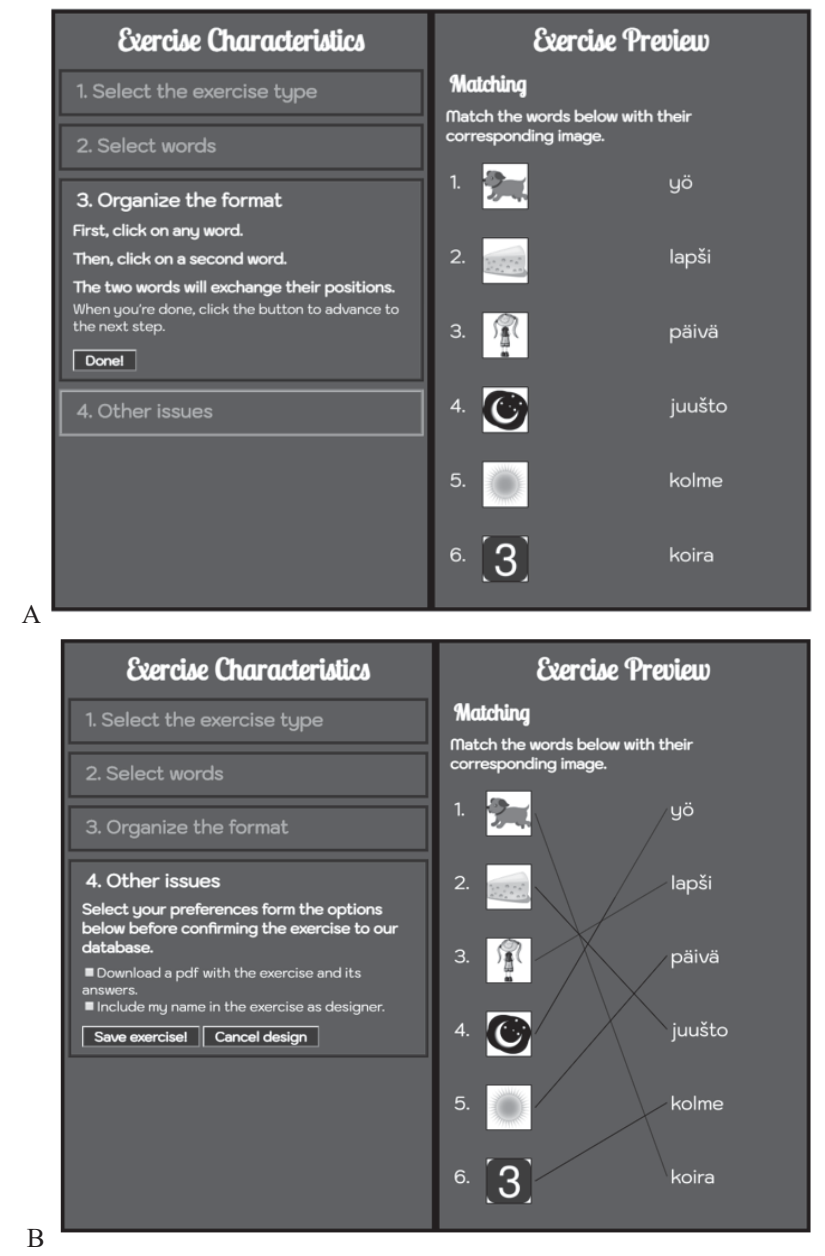

Fig. 25. A) The teacher can re-organize the exercise amd B) when it is ready he/she can save or print it
3) Selection of words - revision of the words: If at the end of the selection, the teachers realize they need more or less words, or that one word does not fit in the exercise, they can retrace their steps and modify the quantity of words in the exercise as well as the specific words selected. (Fig. 24D)

In this step (3. Organize the format) the teachers modify the format of the exercise. In the example below, the teachers interchange the positions of the words on the right so the matching between images and words is not always perfectly straight. (Fig. 25A)

In the last step (4. Finalizing the exercise/Other issues), the teachers confirm that the exercise is ready. In this section they can also get a pdf copy of the exercise (both with the exercise blank and with the answers) or include their name as designer of the exercise. Once saved, the exercise will be added to a database so it can be accessed in two formats: (1) as a downloadable pdf and (2) as an on-line game. (Fig. 25B)

\section{DISCUSSION}

In this paper, we have presented several online games developed for beginners to learn Viena Karelian. We have also evaluated these games with five participants who belong to different age groups. In addition, we introduce a tool concept for teachers to create exercises in an easy way without any programming knowledge. According to our knowledge, there are not many existing mobile or online games to learn Viena Karelian dialect and culture [13], [14]. Karelian is classified as a minority and endangered language. Therefore, different actions for revitalizing the Karelian language and culture are needed. We see digital games and gamified solutions as ways to update, learn and maintain Karelian language and provide easy access to learn vocabulary. In addition, it is relevant to make content creation to these games accessible, so that the provided vocabularies stay current and/or can be extended to other dialects and language groups.

This study has some limitations. One aspect is the usability and visual design issues of our early prototype level games. Lacks in usability and UI design had some influence on player experiences. Other limitation is the relatively small sample of the participants. However, we selected participants from different age groups and those who have interest and some prior background in learning Viena Karelian. Moreover, each test took from one hour to over two hours and during the test session we were able to walkthrough games and let participants to play them and express their experiences relating to each game. Based on this, we can state that our material is rich, even though the sample is small.

We acknowledge that we cannot generalize our findings, because our sample is small, and these results are specific to a minority language like Karelian language (e.g. similarities between Finnish and Karelian. Each minority language can have their own special characteristics and situations which need to be considered in the game development. 


\section{CONCLUSION}

In this paper, we present different online games developed for beginners to learn Viena Karelian. We also introduce a tool concept for teachers to create exercises for students easily without programming knowledge. Karelian language is classified as an endangered minority language. Therefore, there is a need to create modern activities in near future to provide digital games and gamified ways to learn and use language. According to our knowledge, there are not many existing mobile or online games to learn Viena Karelian dialect and culture, and there is a need for games to be develop for different user and age groups.

In this paper, we also present how five participants from different age groups experienced the games. We want to share these results in order to provide other practitioners and researcher a possibility to utilize these results or find ways to collaborate.

\section{ACKNOWLEDGMENT}

We thank the trainers from Buutti Education and the student from Educational consortium OSAO for developing the games. The second author has received funding from Business Finland funded project Reboot Finland IoT Factory 33/31/2018, supported by Academy of Finland 6Genesis Flagship (318927). We want to thank participants for the valuable feedback.

\section{REFERENCES}

[1] A. Sarhimaa, "Karjalan kieli Suomessa: ELDIA projektin tuloksia". Studies in European Language Diversity 27.1. 2016.

[2] Y. Klementyev, S. Kovaleva, and K. Zamyatin, "The karelian language in russia: An overview of a language in context," Working Papers in European Language Diversity, 12.) Helsinki: ELDIA , Tech. Rep., 2013.

[3] T. Salonen, "Karelian a digital language?" The Digital Language Diversity Project, Tech. Rep., 2017.

[4] A. Sarhimaa, "The karelian language in finland: An overview of a language in context," Working Papers in European Language Diversity, Tech. Rep., 2011.

[5] Kotimaisten Kielten Keskus. Retrieved $12^{\text {th }}$ September 2019, from: https://www.kotus.fi/kotus. 2019.

[6] S. Deterding, "Gamification: designing for motivation," interactions, vol. 19, no. 4, pp. 14-17, 2012.

[7] S. Deterding, R. Khaled, L. E. Nacke, and D. Dixon, "Gamification: Toward a definition," in CHI 2011 gamification workshop proceedings, vol. 12. Vancouver BC, Canada, 2011.

[8] J. Hamari, J. Koivisto, and H. Sarsa, "Does gamification work?--a literature review of empirical studies on gamification," in the 47th Hawaii international conference on system sciences (HICSS), 2014, pp. 3025-3034, doi: 10.1109/HICSS.2014.377.

[9] P. Backlund and M. Hendrix, "Educational games-are they worth the effort? a literature survey of the effectiveness of serious games," in Games and virtual worlds for serious applications (VS-GAMES), 2013 5th international conference on. IEEE, 2013, pp. 1-8.

[10] E. A. Boyle, T. Hainey, T. M. Connolly, G. Gray, J. Earp, M. Ott, T. Lim, M. Ninaus, C. Ribeiro, and J. Pereira, "An update to the systematic literature review of empirical evidence of the impacts and outcomes of computer games and serious games," Computers \& Education, vol. 94, pp. 178-192, 2016.

[11] R. E. Ferdig, Handbook of Research on Effective Electronic Gaming in Education. IGI Global, 2009.
[12] H. W. Giessen, "Serious games effects: an overview," ProcediaSocial and Behavioral Sciences, vol. 174, pp. 2240-2244, 2015.

[13] J-P., Koski and L. Arhippainen, Ukko opaštau lapšie äijän-Serious games as tools for teaching Viena Karelian to Finns?. In The 25nd Conference of Open Innovations Association FRUCT, Helsinki, Finland. 2019, pp. 5-8.

[14] Triando and L. Arhippainen, "Development and User Experiences of the Learn Viena Karelian Mobile Web Game". 2019 International Conference on Advanced Computer Science and information Systems (ICACSIS), Bali, Indonesia, 2019, pp. 465-470, doi: 10.1109/ICACSIS47736.2019.8979925.

[15] Kielimestari application designed by the Northern Sociolinguistic Encounters. Retrieved $16^{\text {th }}$ September 2019 from https://apkpure.com/kielimestari/com.rsg.opikielta

[16] Riputandupačas Retrived $14^{\text {th }}$ September 2019 from https://opastajat.net/opastus/hangman/index.html

[17] Viena: Epic Kalevala Adventure (Version 1.0.1) Retrieved from https://play.google.com/store/apps/details?id=com.RadicalRedGames Viena\&hl=en US 1.10 .2020

[18] "Dictionary of karelian. torikka, m. (1st ed.), joki, 1. (2nd eds.) web application by vihtari, j." http://kaino.kotus.fi/cgi-bin/kks/karjala.cgi, 2009, last update: 2019-02-22. accessed: 2019-03-22.

[19] Uuši vuoši game. Developed by Likopiän Tyttö. Retrieved 14th September 2019 from https://uusivuosi.000webhostapp.com/

[20] K. M. Kapp, The gamification of learning and instruction: gamebased methods and strategies for training and education. John Wiley \& Sons, 2012.

[21] B. H. Sørensen and B. Meyer, "Serious games in language learning and teaching-a theoretical perspective," in DiGRA Conference, 2007.

[22] P. Alavesa and L. Arhippainen, "A Game Palette and Guidelines for Game Development for Minority Languages-Case Karelian." in DiGRA Conference, 2020.

[23] C. Heeter, C. K. Chu, A. Maniar, B. Winn, P. Mishra, R. Egidio, L. Portwood-Stacer et al., "Comparing 14 plus 2 forms of fun (and learning and gender issues) in commercial versus educational space exploration digital games," in International Digital Games Research conference, 2003, pp. 4-6.

[24] Reinhardt and S. Thorne, "Metaphors for digital games and language learning," in The Routledge handbook of language learning and technology, F. Farr and L. Murray, Eds. 2016, pp. 415-430.

[25] S. Suh, S. W. Kim, and N. J. Kim, "Effectiveness of mmorpg-based instruction in elementary english education in korea," Journal of computer assisted learning, vol. 26, no. 5, pp. 370-378, 2010.

[26] G. Stanley and K. Mawer, "Language learners \& computer games: From," TESL-EJ, vol. 11, no. 4, p. n4, 2008.

[27] P. Wouters, E. D. Van der Spek, and H. Van Oostendorp, "Current practices in serious game research: A review from a learning outcomes perspective," in Games-based learning advancements for multi-sensory human computer interfaces: techniques and effective practices. IGI Global, 2009, pp. 232-250.

[28] 10tons. Heroes of Kalevala. 2017. Retrieved $2^{\text {nd }}$ August 2019 from http://www.10tons.com/Game/heroes of kalevala

[29] Samranta. Väinämöisen matka - Kalevala-aiheinen lautapeli. 2016.

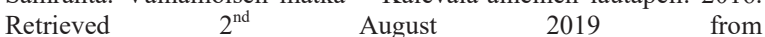
https://oppiavakakaikki.wordpress.com/2016/02/16/vainamoisenmatka-kalevala-aiheinen-lautapeli/

[30] Opetushallitus. Sammon Salat. 2017. Retrieved 2nd August 2019, from http://www03.edu.fi/oppimateriaalit/sammon_salat/index.html

[31] Clipart-library. Retrived 9th September, 2019 from http://clipartlibrary.com/

[32] O. Karlova. (2011). Vienankarjalan alkeiskuršši. Retrieved 30th April, 2019, from http://avtor.karelia.ru/elbibl/karlova/vienankarjalan/index.html\#1

[33] P. Zaikov. (2013). Vienankarjalan kielioppi: lisänä harjotukšie ta lukemisto. Karjalan Sivistysseura ry.

[34] Karakin, J (2017). Karjalua vienakšsi: Vienankarjalan alkeiskuršši. Petroskoi: Periodika

[35] P. Zaikov (1993) Kaunista karjalua 2. Luventakirja vienankarjalaksi. Petroskoi.

[36] O. Karlova (2008) Opaštukka vienankarjalakši. Petroskoi 